\title{
Opposed Phase Imaging as a Diagnostic Biomarker for Differentiating Malignant from Benign Bone Marrow Lesions
}

\author{
HEBA KAMAL, M.D. and NEVIEN EL-LEITHY, M.D. \\ The Department of Diagnostic and Interventional Radiology, Faculty of Medicine, Cairo University
}

\begin{abstract}
Background: The real dilemma in diagnosing osseous lesions, is that benign or even nonneoplastic marrow lesions can demonstrate signal changes similar to malignant lesions. Consequently, biopsy is often demanded for conclusive diagnosis. Hence, the advancement of strong objective methods, such as quantitative biomarkers, is vital clinically for characterization and the follow-up of any bone marrow lesion.

Opposed phase imaging is an example of MR quantitative biomarker technique, being able to detect microscopic fat, and characterizing any marrow lesion based on the amount of fatty marrow infiltrated or preserved.

Aim of Study: To assess the diagnostic efficiency of opposed phase MR imaging and signal intensity ration (SIR) in differentiating as well as characterizing benign and malignant bone marrow lesion, by setting an optimal cut-off value.

Patients and Methods: This was a prospective noncontrolled randomized study, including 65 patients ( 35 men and 30 women, mean age 32 years old), with focal bone marrow lesions. All lesions were studied by conventional, contrast enhanced and opposed phase MR imaging. Chemical shift imaging was carried out by axial in-phase [repetition time (TR), 500ms; echo time (TE), 4.6ms; flip angle, $80^{\circ}$ and out of-phase (TR, $500 \mathrm{~ms}$, TE, $2.3 \mathrm{~ms}$, flip angle, $80^{\circ}$ ). Signal intensity ratio (SIR) was calculated by dividing the out of-phase signal intensity on the in-phase signal intensity.

Results: There was a significant difference $(p<0.001$, independent $t$-test) in the mean SIR for the benign lesions (mean, 0.59; SD, 0.28) compared with the malignant lesions (mean, 0.99; SD, 0.08). ROC analysis yielded optimal cut off values at $>0.93$ correctly differentiating malignant from benign lesions (sensitivity, $94.7 \%$; specificity, $86.6 \%$ ), area under the curve (AUC, 0.888), (positive predictive value, $81.8 \%$ ), (negative predictive value, $96.3 \%)$ and $(95 \%$ confidence interval, 0.765-0.960).

Conclusion: SIR values calculated from opposed phase imaging is a useful diagnostic biomarker for quantitative differentiation of benign from malignant bone marrow lesions, SIR in malignant lesions were higher than benign lesion, with a value of 0.93 can be used as a cut off to differentiate both entities.
\end{abstract}

Correspondence to: Dr. Heba Kamal, The Department of Diagnostic and Interventional Radiology, Faculty of Medicine, Cairo University
Key Words: Bone marrow lesions - Opposed phase imaging - SIR.

\section{Introduction}

MAGNETIC resonance imaging (MRI) has provided higher capabilities and image resolution in studying and diagnosing different bone marrow lesions, in many cases differentiating benign from malignant entities is easily accomplished by MRI, however, some lesions display equivocal character and signal pattern, that makes it challenging to differentiate benign from malignant lesions. Even contrast administration may not be successful in differentiating these lesions, as some lesions, although benign, they enhance, including Schmorl's nodes, hemangiomas, osseous inflammatory lesions and degenerative vertebral endplate changes [1]

Recent advances in MRI techniques with inventing multiple state of the art sequences, have provided excellent MRI studies with higher spatial resolution and tissue contrast, which positively affected the role of MRI in the differentiation of bone marrow lesions of inconclusive nature [2]

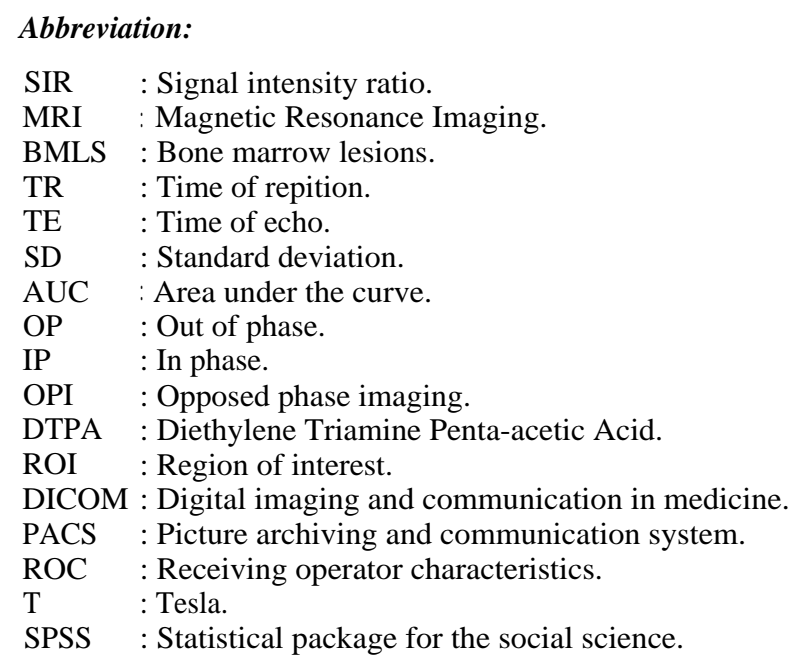


Opposed phase MRI (chemical shift imaging), is a recent MRI technique, which was found very valuable in detecting any small amount of fat in tissues, suggesting its benign nature [3]. Normal bone marrow is known to contain microscopic fat, also it is well established that malignant lesions invade and destroy the bone marrow, while benign lesions preserve bone marrow fat, giving the opposed phase imaging the advantage and ability to differentiate between the two entities [4]

Opposed phase imaging has the capacity to identify the microscopic fat based on different precession frequencies between fat and water protons on in-phase (IP) and out-of-phase (OP) sequences. At IP images the signal from fat and water at a given tissue/voxel are added together, while at OP images of the same voxel both signals are opposing and hence cancel each other, resulting in a signal drop [5]

IP and OP sequences are conveniently generated by using a dual gradient-echo technique with $\mathrm{T} 1$ weighting. Protocol for IP and OP MRI is modified based on the strength of the magnetic field. The images for both sequences can be taken in about 20-30s, or a single breath hold [1]

The purpose of this study was to investigate the potential application of opposed phase imaging (OPI) in characterization and differentiation of various bone marrow lesions raising the level of confidence in differentiating benign from malignant bone lesions and setting a cut-off point to differentiate both entities.

\section{Patients and Methods}

We designed a prospective non-controlled randomized study, including 65 patients (35 men and 30 women, age range from 10 to 75 years old, mean age 32 years old), clinically suspected to have bone tumors, or have incidentally discovered an osseous lesion of equivocal nature, who were referred from the orthopedic outpatient clinic to the Radiology Department, during the time period February 2020 to February 2021. The exclusion criteria, included patients who received chemotherapy or radiotherapy, patients with metallic implants incompatible with MRI, claustrophobic patients, and those with impaired renal functions.

Written and verbal informed consents were obtained from the patient himself in adult cases or the patient's guardian if the patient is a minor or mentally unstable.

All patients included in the study had conventional MRI, opposed phase imaging and Post Gadolinium-DTPA (Diethylene Triamine Penta-acetic Acid) MR imaging.

\section{MRI protocol (Tables 1,2):}

MRI examinations were done on "ACHIEVA 1.5T 109 equipment (from PHILIPS Medical Systems, Best, the 110 Netherlands)" utilizing SenseXL- toros (16 channel) phased array coil for chest and pelvis, and surface coil for the extremities.

Table (1): Pre-contrast MRI sequences.

\begin{tabular}{|c|c|c|c|c|c|}
\hline Survey & Axial T1 & $\begin{array}{l}\text { Axial T2 (TSE) } \\
\text { Turbo spin echo }\end{array}$ & $\begin{array}{l}\text { Coronal T1 } \\
\text { (TSE) Turbo } \\
\text { spin echo }\end{array}$ & $\begin{array}{c}\text { Coronal STIR } \\
\text { (Short time } \\
\text { inversion recovery) }\end{array}$ & $\begin{array}{l}\text { Axial chemical } \\
\text { shift imaging }\end{array}$ \\
\hline $\begin{array}{l}\text { Freq FOV: } 40 \\
\text { Phase FOV: } \\
1.00 \\
\text { Slice thickness: } \\
8 \mathrm{~mm}\end{array}$ & $\begin{array}{l}\text { Scan Plane: Axial } \\
\text { FOV: } \\
\text { (AP=220mm, } \\
\text { RL=230mm) } \\
\text { Slice thickness: } \\
\text { 5mm } \\
\text { Slice Spacing: } \\
1 \mathrm{~mm} \\
\text { Number of slices: } \\
25 \\
\text { TR (average): } \\
500 \text { ms } \\
\text { TE: } 10-15 \mathrm{~ms} \\
\text { TF: } 4 \\
\text { NSA: } 3\end{array}$ & $\begin{array}{l}\text { Scan Plane: Axial } \\
\text { FOV: (AP=220mm, } \\
\text { RL=230 mm) } \\
\text { Slice } \\
\text { thickness: } 5 \mathrm{~mm} \\
\text { Slice } \\
\text { Spacing: } 1 \mathrm{~mm} \\
\text { Number of slices: } 25 \\
\text { TR: } 4000-5000 \mathrm{~ms} \\
\text { TE: } 110-120 \mathrm{~ms} \\
\text { TF: } 17-25 \\
\text { NSA: } 4\end{array}$ & $\begin{array}{l}\text { Scan Plane: Coronal } \\
\text { FOV: } \\
\text { (RL=400mm, } \\
\text { FH=450mm) } \\
\text { Slice } \\
\text { thickness: } 5 \mathrm{~mm} \\
\text { Slice } \\
\text { Spacing: } 1 \mathrm{~mm} \\
\text { Number of slices: } \\
25 \\
\text { Matrix: } 256 \mathrm{x} \\
196 . \\
\text { TR (average): } \\
500 \mathrm{~ms} \\
\text { TE: } 10-15 \mathrm{~ms} \\
\text { TF: } 4 \\
\text { NSA: } 3\end{array}$ & $\begin{array}{l}\text { Scan Plane: Coronal } \\
\text { FOV: } \\
\text { (RL=400mm, } \\
\text { FH=450mm) } \\
\text { Slice } \\
\text { thickness: } 5 \mathrm{~mm} \\
\text { Slice } \\
\text { Spacing: } 1 \mathrm{~mm} \\
\text { Number of slices: } 25 \\
\text { Matrix: } 256 \mathrm{x} \\
\text { 196. } \\
\text { TR (average): } \\
5000 \mathrm{~ms} \\
\text { TE: } 25 \mathrm{~ms} \\
\text { TI: } 160 \mathrm{~ms} \\
\text { TF: } 17 \\
\text { NSA: } 2\end{array}$ & $\begin{array}{l}\text { Scan Plane: Axial } \\
\text { FOV: } \\
\text { (AP=360mm, } \\
\text { RL=398mm) } \\
\text { Slice thickness: } 5 \mathrm{~mm} \\
\text { Slice Spacing: } 1 \mathrm{~mm} \\
\text { Number of slices: } 25 \\
\text { TR (average): } 500 \mathrm{~ms} \\
\text { Out Phase TE: } 2.3 \mathrm{~ms} \\
\text { In Phase TE: } 4.6 \mathrm{~ms} \\
\text { Flip angle: } 80^{\circ} \\
\text { NSA: } 4\end{array}$ \\
\hline
\end{tabular}


Table (2): Post-contrast MRI sequences.

\begin{tabular}{lll}
\hline Axial T1 post contrast & \multicolumn{1}{c}{$\begin{array}{c}\text { Thrive }(\mathrm{T} 1 \text { wieghted high } \\
\text { resolution isotropic volume } \\
\text { excitation fast gradient, 3D \& Fat-sat). }\end{array}$} & Sagittal T1 post contrast \\
\hline Scan Plane: Oblique & FOV: $(\mathrm{AP}=220 \mathrm{~mm}, \mathrm{RL}=220 \mathrm{~mm})$ & Scan Plane: Sag \\
FOV: $(\mathrm{AP}=220 \mathrm{~mm}, \mathrm{RL}=230 \mathrm{~mm})$ & Matrix size: $300 \times 300$ & FOV: $(\mathrm{AP}=300 \mathrm{~mm}, \mathrm{FH}=300 \mathrm{~mm})$ \\
Slice thickness: $5 \mathrm{~mm}$ & Slice thickness: $3.6 \mathrm{~mm}$. & Slice thickness: $5 \mathrm{~mm}$ \\
Slice Spacing: $1 \mathrm{~mm}$ & 3D thickness=3 & Slice Spacing: $1 \mathrm{~mm}$ \\
Number of slices: 25 & Slice Spacing: $0 \mathrm{~mm}$ & Number of slices: 25 \\
TR: $450-650 \mathrm{~ms}$ & TR: $4.5 \mathrm{~ms}$ & TR: $450-650 \mathrm{~ms}$ \\
TE: $10-16 \mathrm{~ms}$ & TE: $2.2 \mathrm{~ms}$ & TE: $10-16 \mathrm{~ms}$ \\
NSA: 2 & NSA: 4 & NSA: 3 \\
\hline
\end{tabular}

\section{Image analysis and interpretation:}

For data interpretation, all images were sent to a workstation using the Digital Imaging and Communications in Medicine (DICOM) format.

I- Conventional and contrast enhancing MR analysis:

The lesion is identified on conventional MRI and the morphological features of each lesion were recorded including:

- Site: Either appendicular or axial and subsequently the specific site in each entity was detected. Site within the bone either epiphyseal, metaphyseal or diaphyseal.

- Signal characteristics on T1- and T2-weighted images:

- On T 1 WIs lesions with a signal that is lower than, equal to or higher than that of muscle were considered as having low, intermediate or high T 1 signal respectively.

- On the other hand, on T2WIs lesions having a signal lower than that of muscle were considered as having a low signal intensity; those with a signal that is equal to or higher than that of muscle but less than that of fat were identified as having an intermediate signal; while lesions with a signal higher than that of fat were considered as highsignal lesions.

- Tumor breakdown: Either cystic breakdown, internal hemorrhagic areas or calcific foci within the tumoral tissue.

- Pattern and intensity of contrast uptake in the contrast-enhanced imaging:

Lesions were divided into non-enhancing, homogeneously or heterogeneously enhancing lesions. The intensity of enhancement was graded as being mild, moderate or marked (avid).

\section{II- Opposed phase imaging analysis: \\ a- Qualitative analysis:}

This was done by comparing the morphological changes in signal intensity between the in and out phase sequences, results were divided into lesions with signal drop and lesions showing no signal drop in out-phase images relative to the in-phase images.

\section{b- Quantitative analysis:}

Signal intensity ratio (SIR):

Quantitative assessment of signal intensity for each lesion by two different regions of interests (ROI). The first region of interest was done in the out-phase images to limit the miscalculation via inclusion of the rim of chemical shift artifact found at the interface between fat and water containing tissues in the out-phase images. Identical ROI was placed at the in-phase images.

Signal intensity of the minimum, maximum and average values were obtained for both in and out phase images. the average value was the mainstay for assessment. At least three measurements were acquired from different locations for each sequence and the average value was taken into consideration to prevent bias.

SIR was calculated by dividing the out-phase signal by the in-phase signal using the following formula, out phase signal/in phase signal.

To ensure that the same areas were measured, regions of interest were carefully redrawn from out-phase to in-phase images.

\section{Statistical analysis:}

Statistical analysis was performed using the statistical software: SPSS statistical package version 20 (SPSS Inc., Chicago, IL). 
Numerical data were formulated as mean and standard deviation or median and range as appropriate. Qualitative data were expressed as frequency and percentage.

ROC analysis (Receiver Operator Characteristic) was done to select the best cutoff point for SIR.

The findings on MRI were analyzed and correlated with histopathological findings after needle biopsy or resection surgical biopsy or lesions which were deemed benign in respect to their behavior on at least six months follow-ups.

Mean average SIR values were selected for statistical analysis and compared with the histopathological results.

\section{Statistical methods:}

Standard diagnostic indices including sensitivity, specificity, positive predictive value (PPV), negative predictive value (NPV) and diagnostic efficacy were calculated. ROC curve was constructed with area under curve analysis performed to detect best cut-off value of SIR for detection of residue. For comparing categorical data, Exact test was used instead when the expected frequency is less than 5. Chi square $\left(\mathrm{X}^{2}\right)$ test was performed. $p$-value less than 0.05 was considered as statistically significant.

\section{Results}

All the malignant bone lesions encountered in our study were pathologically proven while the benign lesions; ten lesions were pathologically proven and the rest were deemed benign on regular follow-up scans for six months.

\section{Pathology:}

We had 65 patients that were categorized into 27 malignant lesions $(41 \%)$ and 38 benign lesions (59\%), as shown in the following Pie (Fig. 1), with Tables $(3,4)$ showing the distribution of each category.

\section{Conventional MRI characteristics of benign and malignant lesions:}

The different signal characteristics of benign and malignant bone marrow lesions in the different MRI sequences is outlined in Table (5), with malignant lesions showing more intense contrast enhancement, as well as more intra lesional hemorrhage, and calcifications.
Table (3): The distribution of benign pathologies and mean age of each.

\begin{tabular}{|c|c|c|c|c|}
\hline Pathology & Category & $\begin{array}{l}\text { Number } \\
\text { of cases }\end{array}$ & $\begin{array}{l}\text { Mean age } \\
\text { (in years) }\end{array}$ & $\begin{array}{l}\text { Age range } \\
\text { (in years) }\end{array}$ \\
\hline Osteochondroma & Bening & 9 & 25.5 & $9-30$ \\
\hline $\begin{array}{l}\text { Fibrous cortical } \\
\text { defect }\end{array}$ & Bening & 5 & 25.3 & $16-41$ \\
\hline $\begin{array}{l}\text { Non-ossifying } \\
\text { fibroma }\end{array}$ & Bening & 4 & 11.5 & $9-14$ \\
\hline Giant cell tumor & Bening & 3 & 20.25 & $16-36$ \\
\hline Fibrous dysplasia & Bening & 3 & 16 & 16 \\
\hline Hemangioma & Bening & 8 & 52.6 & $43-67$ \\
\hline Enchondroma & Bening & 1 & 20 & 20 \\
\hline Avascular necrosis & Bening & 3 & 30.25 & $15-52$ \\
\hline Pott's disease & Bening & 1 & 16 & 16 \\
\hline Osteomyelitis & Bening & 1 & 31 & 31 \\
\hline
\end{tabular}

Table (4): The distribution of malignant pathologies and mean age of each.

\begin{tabular}{|c|c|c|c|c|}
\hline Pathology & Category & $\begin{array}{l}\text { Number } \\
\text { of cases }\end{array}$ & $\begin{array}{l}\text { Mean age } \\
\text { (in years) }\end{array}$ & $\begin{array}{l}\text { Age range } \\
\text { (in years) }\end{array}$ \\
\hline Osteosarcoma & Malignant & 5 & 13.2 & $6-23$ \\
\hline $\begin{array}{c}\text { Plasma cell } \\
\text { myeloma }\end{array}$ & Malignant & 5 & 45.3 & $38-53$ \\
\hline Metastasis & Malignant & 12 & 42.5 & $17-67$ \\
\hline Ewing sarcoma & Malignant & 5 & 14.3 & $8-19$ \\
\hline
\end{tabular}

Table (5): MRI characteristics of Benign and Malignant bone lesions.

\begin{tabular}{lllll}
\hline $\begin{array}{l}\text { Signal intensity } \\
\text { at T1-weighted } \\
\text { imaging }\end{array}$ & \multicolumn{3}{c}{ Benign } & Malignant \\
\hline $\begin{array}{l}\text { Hypo-intense } \\
\text { Intermediate intensity }\end{array}$ & $12 / 38$ & $31 \%$ & $7 / 27$ & $25 \%$ \\
Hyper-intense & $8 / 38$ & $48.2 \%$ & $16 / 27$ & $60 \%$ \\
Signal intensity at & & & & \\
T2-weighte image: & & & & \\
$\quad$ Hypo-intense & $5 / 38$ & $13.8 \%$ & $4 / 27$ & $15 \%$ \\
$\quad$ Intermediate intensity & $18 / 38$ & $48.2 \%$ & $19 / 27$ & $70 \%$ \\
$\quad$ Hyper-intense & $15 / 38$ & $38 \%$ & $4 / 27$ & $15 \%$ \\
Contrast enhancement & & & & \\
pattern: & & & & \\
$\quad$ Homogeneous & $13 / 20$ & $66.6 \%$ & $14 / 27$ & $51.8 \%$ \\
$\quad$ Heterogeneous & $7 / 20$ & $33.4 \%$ & $13 / 27$ & $48.2 \%$ \\
Contrast enhancement & & & & \\
intensity: & & & & \\
$\quad$ Non-enhancing & $18 / 38$ & $4.2 \%$ & 0 & $0 \%$ \\
$\quad$ Faint & $12 / 38$ & $31.2 \%$ & $4 / 27$ & $15 \%$ \\
$\quad$ Moderate & $4 / 38$ & $10.3 \%$ & $9 / 27$ & $35 \%$ \\
$\quad$ Avid & $4 / 38$ & $10.3 \%$ & $14 / 27$ & $50 \%$ \\
$\quad \begin{array}{llll}\text { Intra-lesional breakdown } \\
\text { and cystic changes: }\end{array}$ & & & & \\
$\quad$ Non & $29 / 38$ & $75 \%$ & $17 / 27$ & $63.6 \%$ \\
$\begin{array}{l}\text { Cystic } \\
\text { Hemorrhage }\end{array}$ & $7 / 38$ & $17.9 \%$ & $3 / 27$ & $11.1 \%$ \\
\hline & $1 / 38$ & $3.6 \%$ & $4 / 27$ & $14.8 \%$ \\
\hline & & & &
\end{tabular}


Opposed phase imaging analysis:

I- Qualitative analysis:

Qualitative analysis was done to morphologically differentiate lesions that demonstrated signal drop in out-phase (OP) images compared to inphase images (IP) versus those which did not exhibit signal drop in the same set of images in benign versus malignant categories as shown in Table (6).

It was found that $86 \%$ of benign lesions in our study exhibited signal drop in OP images compared with IP images (Fig. 2), while 95\% of malignant lesions didn't exhibit similar signal drop (Fig. 3).

\section{II- Quantitative analysis:}

Quantitative assessment of the in and out phase signal intensities revealed statistically insignificant correlation between such values, the mean of malignant lesions out-phase signal was $183.3 \pm 135$ while that of in-phase signal was $187.7 \pm 141.6$, the mean of benign lesions out-phase signal was $179 \pm 140.8$ while that of in phase signal was $240.5 \pm$ 125.3 as shown in Table (7).

Quantitative assessment of the signal intensity ratio was done using the formula, SIR=Out phase signal/In phase signal. There was statistically significant difference between the mean of Signal intensity ratio (SIR) of that of the malignant lesions $(0.99 \pm 0.08)$ and that of benign lesions $(0.59 \pm 0.28)$ ( $p$-value less than 0.001 , independent $t$-test). As shown in Table (8), Figs. $(4,5)$.

Receiver operator characteristics (ROC) was done to assess an optimal cut off value between benign and malignant bone lesions based on the signal intensity ratio using the pathology and long term follow up of benign lesions as gold standard. As shown in Table (9).

Table (6): Showing difference in qualitative drop of signal and nondrop of signal in benign versus malignant lesions.

\begin{tabular}{lllll}
\hline & \multicolumn{3}{c}{$\begin{array}{c}\text { Qualitative assessment of } \\
\text { chemical shift imaging }\end{array}$} \\
\cline { 2 - 5 } & \multicolumn{2}{c}{ Benign } & \multicolumn{2}{c}{ Malignant } \\
\hline Drop of signal & $33 / 38$ & $86.2 \%$ & $1 / 27$ & $5 \%$ \\
No drop of signal & $5 / 38$ & $13.8 \%$ & $26 / 27$ & $95 \%$ \\
\hline
\end{tabular}

Table (7): Shows mean and standard deviation of in and out phase signal values for benign and malignant lesions.

\begin{tabular}{lcccccc}
\hline & \multicolumn{2}{c}{ Benign lesions } & & \multicolumn{2}{c}{ Malignant lesions } \\
\cline { 2 - 3 } \cline { 5 - 6 } & \multicolumn{2}{c}{ Out phase } & In phase & & Out phase & In phase \\
\hline Mean & 179 & 240.5 & & 183.3 & 187.7 \\
Standard deviation & 140.8 & 125.3 & & 135 & 141.6 \\
\hline
\end{tabular}

Table (8): The mean and standard deviation of SIR of benign and malignant lesions.

\begin{tabular}{lcc}
\hline & \multicolumn{2}{c}{$\begin{array}{c}\text { Mean and standard deviation of SIR in } \\
\text { benign and malignant lesions }\end{array}$} \\
\cline { 2 - 3 } & Benign & Malignant \\
\hline Mean & 0.99 & 0.59 \\
Standard deviation & 0.08 & 0.28 \\
\hline
\end{tabular}

Table (9): ROC curve analysis between benign and malignant lesions based on pathology.

\begin{tabular}{cccccccc}
\hline $\begin{array}{c}\text { Cut-off } \\
\text { point }\end{array}$ & AUC & Sensitivity & Specificity & $-\mathrm{PV}$ & $+\mathrm{PV}$ & $\begin{array}{c}p- \\
\text { value }\end{array}$ & $\begin{array}{c}95 \% \text { Confidence } \\
\text { interval }\end{array}$ \\
\hline$\geq 0.93$ & 0.888 & 94.74 & 86.67 & 96.3 & 81.8 & 0.001 & $0.765-0.960$ \\
\hline
\end{tabular}

The cut-off value of signal intensity ratio was calculated from $86 \%$ of benign lesions (demonstrating signal drop) and $95 \%$ of malignant lesions (with no signal drop) and was found to be around 0.93 as shown in (Fig. 6).

- The lesions that showed SIR values of more than or equal to 0.93 were mostly categorized as malignant.

- The lesions which showed values less than 0.93 were mostly categorized as benign.

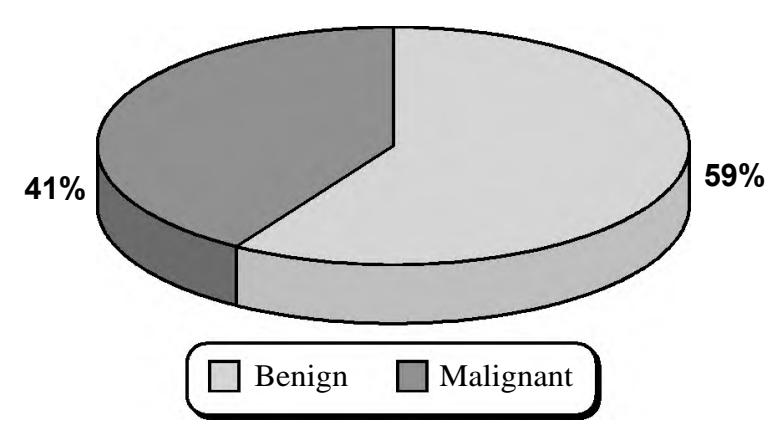

Fig. (1): Percentage of malignant versus benign bone marrow lesions. 

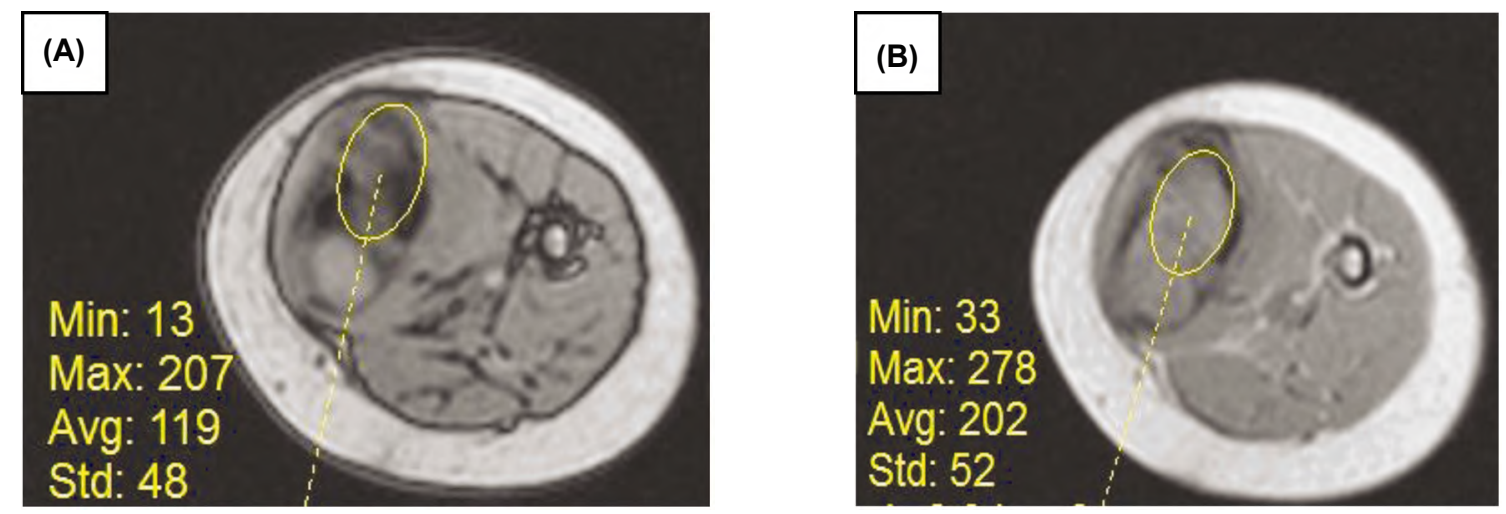

Fig. (2A,B): Axial out and in phase images showing a region of interest within the medullary portion of the affected left tibial bone at both images respectively. It showed decrease in average out phase signal being 119 compared to in phase signal value of 202 with an estimated $S I R=0.74$. The lesion was proven pathologically as Non-ossifying fibroma.
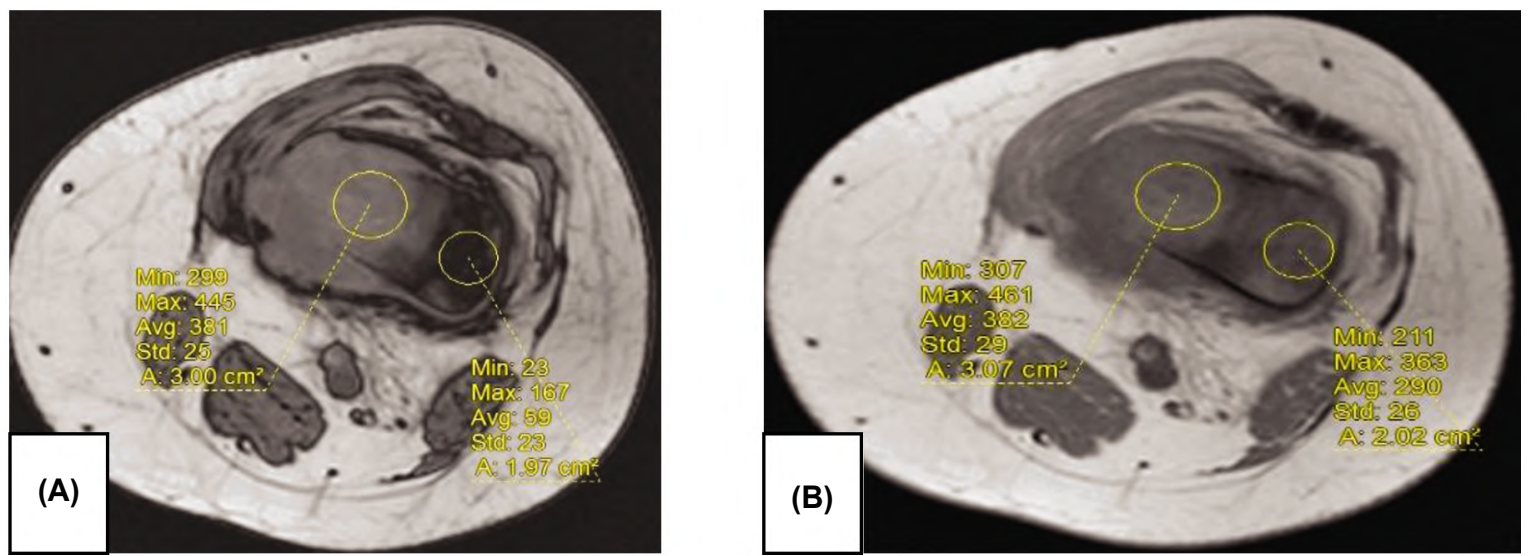

Fig. (3A,B): Axial out and in phase images showing a region of interest within the medullary portion of the distal femoral shaft, with part of the bone marrow seen infiltrated by mass (red arrows). The infiltrated marrow at the out-phase signal (381) nearly showed no signal drop compared to in phase signal (382) with estimated SIR $=1$. On the other hand, the adjacent non infiltrated marrow showed significant signal drop in out phase images (59) compared to in phase images (290) with estimated $\mathrm{SIR}=0.2$. This lesion was pathologically proven distal femoral osteosarcoma.
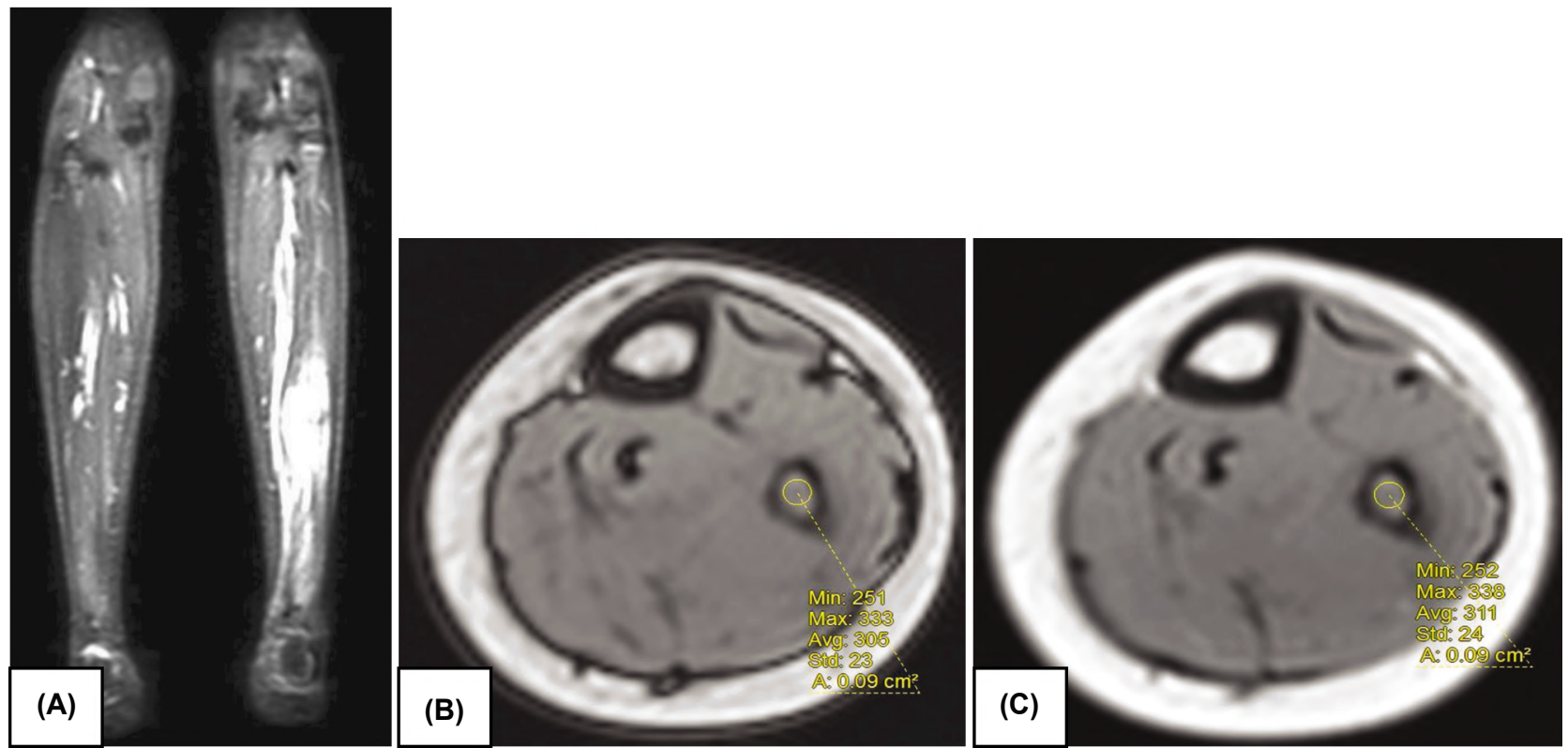

Fig. (4): Coronal STIR (A), showing distal fibular diaphyseal high STIR signal intensity infiltrative mass lesion (red arow). Axial (B\&C): Out phase and in phase images illustrating a region of interest within the medullary portion of the distal fibula. There was no significant signal drop in out phase, the out-phase signal was 305 in average which was slightly lower than that of in phase signal (311) and estimated SIR was 0.98. Pathologically proven left fibular Ewing Sarcoma. 

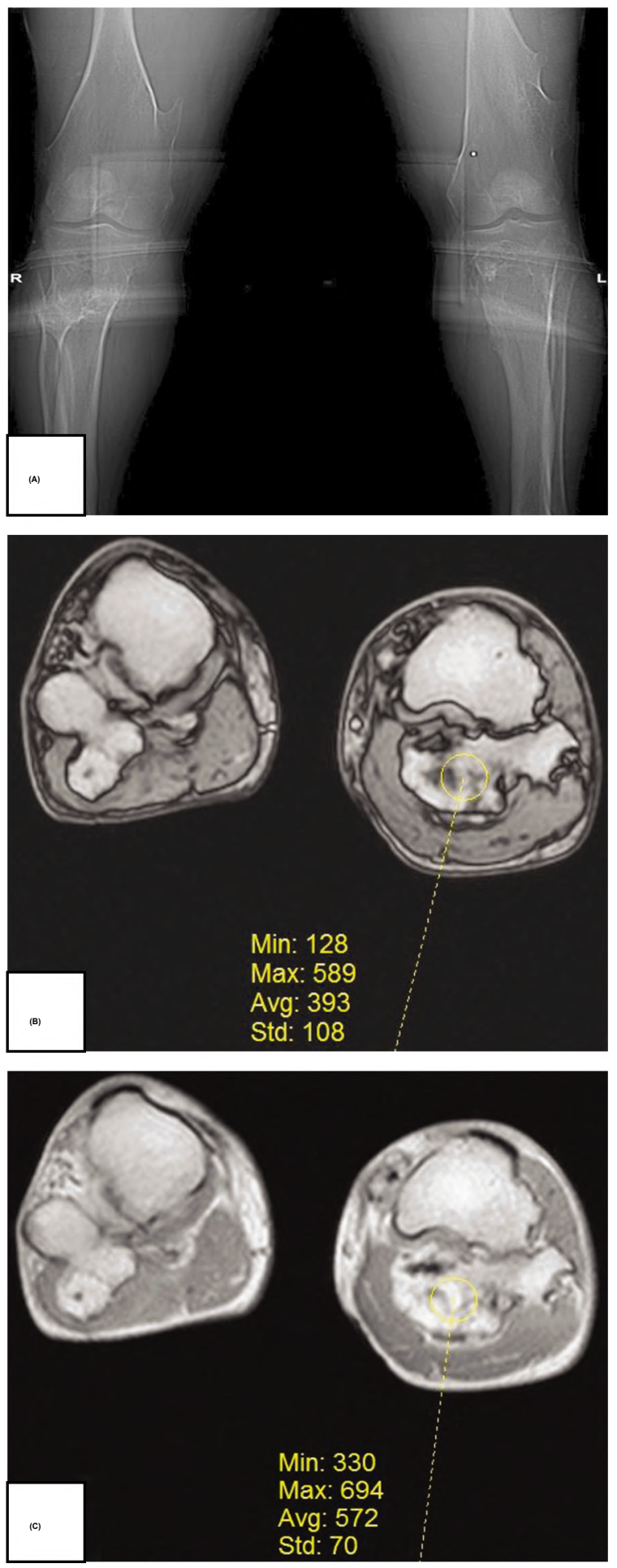

Fig. (5): AP Xray view of both lower limbs (A): showed multiple bilateral bony exostoses arising from distal femur and proximal tibia and fibula. Axial (B\&C) out and in phase images showing a region of interest within the medullary portion of the affected left fibular bone at both images respectively. It showed markedly decreased out phase signal being 393 compared to in phase signal value of 572 with an estimated $\mathrm{SIR}=0.68$. Proven to be osteochondromas.

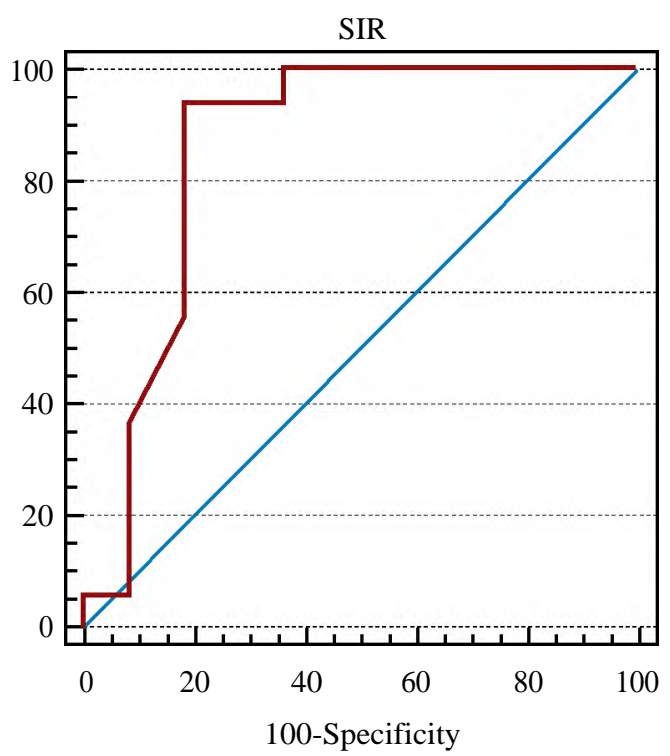

Fig. (6): ROC curve showing Cut off, sensitivity and specificity of SIR between benign and malignant bone lesions.

\section{Discussion}

Magnetic resonance imaging (MRI) has an imperative role in the discovery, characterization, delineation of any bone marrow lesion, therapeutic follow-up, post therapy assessment and prognosis [6]. The mainstay of conventional MRI is to a great extent dependent on the qualitative and subjective interpretation of signal variations in $\mathrm{T} 1$ and $\mathrm{T} 2$ image. The real dilemma in diagnosing osseous lesions, is that benign or even nonneoplastic marrow lesions can demonstrate signal changes similar to malignant lesions [7]. Consequently, biopsy is often demanded for conclusive diagnosis [8]. Subsequently, the advancement of strong objective methods, such as quantitative biomarkers, is vital clinically for characterization and the follow-up of any bone marrow lesion [9] .

Opposed phase imaging is an example of MR quantitative biomarker technique, being able to detect microscopic fat, and characterizing any marrow lesion based on the amount of fatty marrow infiltrated or preserved [9].

The principle of this study was to establish a noninvasive method to differentiate benign and indeterminate bone marrow lesions from malignant ones, by means of quantitative biomarker, through establishing a cut-off value for SIR on chemical shift MRI. 
The sample size of this prospective study included 65 patients 38 lesions (59\%) were benign, while 27 lesions (41\%) were malignant. The mean age of patients was 32 years.

Out of the 38 benign bone lesions 10 were pathologically proven while 28 lesions were deemed benign based on regular follow-ups for at least six months, such selection criterion is comparable with that of the study done by Berry E et al., [1], yet they deemed the benignity of the lesions based on 9 months follow-up duration. On the other hand, all of the malignant lesions were pathologically proven [1].

Most of the benign lesions (30) (79.8\%) showed intermediate to low $\mathrm{T} 1$ signal intensity, The outcomes conform with the expected T1 signal pattern of benign lesions being low to iso intense signal, congruent with the results of Silva, et al., [10] while 8 lesions $(20.2 \%)$ showed high T 1 signal intensity 7 of them were predominantly lipomatous hemangiomata which was congruent with WoottonGorges, [11]. The remaining lesion was giant cell tumor which had hemorrhagic breakdown explaining its high $\mathrm{T} 1$ signal intensity which was in agreement with the description of the study done by Purohit, et al., [12].

Similarly most of the malignant lesions (23) (85\%) showed low T1 signal while only 4 lesions (15\%) were hyperintense on T1WI, 2 lesions were metastatic, 2 lesions were primary osteosarcoma, all could be explained by the tumor hemorrhagic break down, such explanation is matching the description of Kaste [13].

The majority of benign lesions (33) (86.2\%) showed intermediate to high $\mathrm{T} 2$ signal intensity as expected in most benign cases congruent with Stein-Wexler et al., [14]. While the minority of lesions (5) showed low T2 signal intensity which were as follows, 2 lesions were avascular necrosis, 1 lesion was fibrous dysplasia and 2 lesions were giant cell tumor. The 2 lesions of avascular necrosis are matching Manenti, et al., [15], while fibrous dysplasia had intermediate to low $\mathrm{T} 1$ signal intensity and heterogenous T2 signal intensity owing to its calcific content agreeing with the results of Wootton-Gorges, [11]. The aforementioned giant cell tumor which had an abnormally high $\mathrm{T} 1$ signal intensity had also an abnormally low T2 signal intensity which also could be explained by its hemorrhagic component which was congruent with Purohit, et al., [12] and Alyas, et al., [16]

As for malignant lesions the majority (23 lesions) $(85 \%)$ showed intermediate to high $\mathrm{T} 2$ signal intensity while 4 lesions (15\%) showed low T2 signal intensity all of them were well differentiated osteosarcomas having internal sclerotic components, such results are in agreement with the description of Kaste, [13]

Out of the 38 benign bone lesions 18 lesions $(48.2 \%)$ showed no enhancement, 12 lesions (31.2\%) showed faint enhancement, 4 lesions $(10.3 \%)$ showed mild enhancement analogous to the description of Silva et al., [10], while 4 lesions $(10.3 \%)$ also showed avid contrast enhancement that were all giant cell tumors which conforms the description of Purohit, et al., [12] and Alyas, et al., [16].

Out of the 27 malignant lesions 14 lesions (50\%) showed avid contrast enhancement while 9 lesions $(35 \%)$ showed moderate contrast enhancement coinciding with the description of Silva et al., [10] and Wootton-Gorges, [11], only 4 lesions (15\%) showed faint contrast enhancement.

Out of the 20 benign bone lesions that showed contrast enhancement, 13 lesions (66.6\%) have shown homogeneous enhancement, while 7 lesions (33.4\%) have shown heterogeneous enhancement, which is in agreement with Lee, Yu Jin, et al., [17], while $48.2 \%$ of the malignant lesions (13 lesions) have shown heterogeneous pattern of enhancement analogous to the description of Barnardt \& Roux, [18], on the other side $51.8 \%$ of cases (14 lesions) have shown homogeneous enhancement, this matches Keraliya et al., [19] .

Qualitative assessment of signal drop in out phase images compared to the in-phase images was done and lesions were classified as having signal drop or not having signal drop in out phase images.

Out of the 38 benign lesions, 33 lesions ( $86.2 \%)$ have shown signal drop in out phase images while 5 lesions (13.8\%) did not show signal drop in the same set of images, in malignant lesions 26 lesions $(95 \%)$ showed no signal drop while one lesion (5\%) showed signal drop in out phase images. Out of the 5 benign lesions, one case was fibrous dysplasia which actually showed a signal increase in out phase images, this could be explained by the presence of intralesional calcifications which was congruent with Wootton-Gorges, [11] and Shetty AS, et al., [5]. The other case was giant cell tumor which had hemorrhagic component had also increased signal in out phase images owing to the presence of intralesional hemorrhage matching the justifications and descriptions of Shetty AS, et al., [5] and Purohit, et al., [12]. Two lesions were en- 
chondroma which unexpectedly showed almost no signal drop this could be explained by the predominant cartilaginous component over the fatty component in such lesion conforming with the description of Bierry et al., [20] .

The last lesion was Pott's disease of the spine which did not show appreciable qualitative signal drop yet on quantitative analysis it showed $6.7 \%$ quantitative signal drop in out phase images. To our knowledge the signal characteristics of chemical shift imaging of Pott's disease of the spine has not been fully reviewed in literature.

The only malignant lesion which showed signal drop in out phase images was a case of periosteal osteosarcoma which showed SIR 0.75 this could be explained by the lack of marrow invasion so no loss of the normal marrow fat was depicted which was congruent with Murphey, et al., [21]

On the other hand, the quantitative assessment of the signal drop was done by assessment of the signal intensity ratio (SIR) as done by Akman B et al., [22] \& Amin, et al., [23].

Amin, et al., [23], proposed that ROC analysis of mean SIR for 25 benign and 38 malignant lesions, yielded threshold cut off value of 0.75 where malignant lesions were defined to be more than 0.75 and benign lesions were defined to be less than 0.75 with sensitivity, specificity, and AUC of $70.3 \%, 76.5 \%$, and 0.694 for differentiating benign and malignant histology, respectively.

Akman B, et al., [22], selected a cut off point for SIR between benign and malignant vertebral lesions at value of 0.82 , where values less than 0.82 are presumed benign while values higher are presumed malignant using the pathology as gold standard for comparison.

We followed the research model proposed by Akman B, et al., [22] which used ROC curve analysis to determine cut off value of SIR to differentiate malignant from benign lesions.

Our results showed that there was a statistically significant difference between the mean of signal intensity ratio of the malignant lesions $(0.99 \pm 0.08)$ and that of the benign lesions $(0.59 \pm 0.28)$ ( $p$-value less than 0.001 , independent $t$-test). The results also set an optimal cut off value for SIR at 0.93 with values greater than or equal to 0.93 considered malignant and values less than 0.93 considered benign, this yielded $94.7 \%$ sensitivity, $86.7 \%$ specificity with area under the curve (AUC) 0.888 with the 95\% confidence interval (0.765-0.960) and estimated $p$-value of (less than 0.001 , independent $t$-test).

This cut off value correctly diagnosed 26/27 malignant lesions where the only lesion that was misdiagnosed as benign using SIR was a case of periosteal osteosarcoma as mentioned before and had an estimated SIR of 0.75 . While it correctly diagnosed 33/38 benign bone lesions, the 5 lesions that were misdiagnosed as malignant were discussed in details above, they were as follows, 1 case of fibrous dysplasia (SIR=1.1), 1 case of Potts disease $(\mathrm{SIR}=0.94), 1$ case of giant cell tumor $(\mathrm{SIR}=1.15)$ and 2 cases of enchondroma $(\mathrm{SIR}=1)$.

Ogura, et al., [24] had set the cut-off point at 1 and measured the sensitivity and specificity upon this point, we had nearly congruent results however they did not presume ROC curve analysis of such cut off point. Moreover, our study had superior sensitivity and specificity.

One pitfall of our study was the inclusion of 7 typical hemangiomas which contains predominant amounts of fat over vascular components eliciting high $\mathrm{T} 1$ and $\mathrm{T} 2$ signal intensity with suppression of signal in fat suppression sequences which was congruent with Wootton-Gorges, [25] \& Ropper et al., [26], however our sample compensated for such pitfall by including 1 atypical hemangioma that elicited low T 1 and high T2 signal intensity yet it still had a substantial $75 \%$ signal drop in out phase images compared to in phase images with estimated $(\mathrm{SIR}=0.24)$ this particular finding coped with Shi, et al., [27].

Another pitfall was that out of 38 benign bone lesions only 10 lesions were pathologically proven while the rest only depended on morphological criteria and near stability on follow-up, however this reflects the actual daily practice as only a small proportion of benign lesions are biopsied on the other hand, all of the malignant lesions were pathologically proven and diagnosis was merely dependent on histopathology which was in keeping with the study plane of Douis, et al., [28]

One last pitfall was that the sample size was small which might not reflect the entire population raising the importance of future more expanded researches, moreover the benign lesions predominated in our study which might have formed a sort of selection bias yet this could be attributed to the relative rarity of malignant bone lesions compared to benign lesions which reflects our daily practice which coped with the pitfalls of Douis, et al., [28] 


\section{Conclusions:}

This study demonstrated that signal intensity ratio values between Out-Phase and In-phase images (opposed phase MR imaging) was effective for quantitatively differentiate benign from malignant bone marrow lesions, with high specificity and sensitivity. On the other hand, different pathologies exhibit variable behaviors at chemical shift MR imaging. Our results suggested that the SIR values in malignant lesions $(0.99 \pm 0.08)$ were greater than benign lesions $(0.59 \pm 0.28)$ and a value of 0.93 can be used as a cut off to differentiate between benign and malignant focal lesions.

\section{References}

1- BARRY E. KENNEALLY, CHRISTINA J. GUTOWSKI, ALAN W. REYNOLDS, WILLIAM B. MORRISON and JOHN A. ABRAHAM: Utility of opposed-phase magnetic resonance imaging in differentiating sarcoma from benign bone lesions. Journal of Bone Oncology, 4 (4): 110 114,ISSN 2212-1374, https://doi.org/10.1016/j.jbo.2015 10.001, 2015.

2- VILANOVA J.C., BALEATO-GONZALEZ S., ROMERO M.J., CARRASCOSO-ARRANZ J. and LUNA A.: Assessment of Musculoskeletal Malignancies with Functional MR Imaging. Magnetic Resonance Imaging Clinics of North America, 24 (1): 239-259, 2016.

3- KRANSDORF M.J. and BRIDGES M.D.: Current developments and recent advances in musculskeletal tumor imaging. Sem. Musculoskel. Radiol., 17: pp. 145-155, 2013.

4- KENNEALLY B.E., GUTOWSKI C.J., REYNOLDS A.W., MORRISON W.B. and ABRAHAM J.A.: Utility of opposed-phase magnetic resonance imaging in differentiating sarcoma from benign bone lesions. Journal of Bone Oncology, 4 (4): 110-114, 2015.

5- SHETTY A.S., SIPE A.L., ZULFIQAR M., TSAI R., RAPTIS D.A., RAPTIS C.A. and BHALLA S.: In-Phase and Opposed-Phase Imaging: Applications of Chemical Shift and Magnetic Susceptibility in the Chest and Abdomen. RadioGraphics, 39 (1): 115-135, 2019.

6- FAYAD L.M., JACOBS M.A., WANG X., CARRINO J.A. and BLUEMKE D.A.: Musculo-skeletal tumors: How to use anatomic, functional, and metabolic MR techniques. Radiology, 265: 340-356, 2012.

7- PARK S., KWACK K.S., CHUNG N.S., HWANG J., LEE H.Y. and KIM J.H.: Intravoxel incoherent motion diffusion-weighted magnetic resonance imaging of focal vertebral bone marrow lesions: Initial experience of the differentiation of nodular hyperplastic hematopoietic bone marrow from malignant lesions. Skeletal Radiol., 46: 675-683, 2017.

8- ERLEMANN R., REISER M.F., PETERS P.E., et al.: Musculoskeletal neoplasms: Static and dynamic GdDTPA-enhanced MR imaging. Radiology, 171: 767-773, 1989.

9- TAKESHI FUKUDA M.D., KENNETH WENGLER M.S., RUBER DE CARVALHO M.D., et al.: MRI Biomarkers in Osseous Tumors. J. Magn. Reson. Imaging, 50: 702$718,2019$.

10- SILVA F.D., PINHEIRO L., CRISTOFANO C., DE OLIVEIRA SCHIAVON J.L. and LEDERMAN H.M.: Magnetic Resonance Imaging in Pediatric Bone Tumors. Current Radiology Reports, 2 (12): 77, 2014.

11- WOOTTON-GORGES S.L.: Tumors and Tumor-Like Conditions of Bone. In R. Stein-Wexler, S.L. WoottonGorges \& M.B. Ozonoff (Eds.), Pediatric Orthopedic Imaging, (pp. 679-714). Springer Berlin Heidelberg, 2015.

12- PUROHIT S. and PARDIWALA D.N.: Imaging of giant cell tumor of bone. Indian Journal of Orthopaedics, 41 (2): 91-96. https://doi.org/10.4103/0019-5413.32037, 2007.

13-KASTE S.C.: Imaging pediatric bone sarcomas. Radiologic Clinics of North America, 49 (4): 749-765, vi-vii, 2011.

14- STEIN-WEXLER R., WOOTTON-GORGES S.L. and OZONOFF M.B.: Pediatric orthopedic imaging. In Pediatric Orthopedic Imaging, 45: 1258-1259, 2015.

15- MANENTI G., ALTOBELLI S., PUGLIESE L. and TARANTINO U.: The role of imaging in diagnosis and management of femoral head avascular necrosis. Clinical Cases in Mineral and Bone Metabolism, 12 (Suppl 1): 31, 2015.

16-ALYAS F., JAMES S.L., DAVIES A.M. and SAIFUDDIN A.: The role of MR imaging in the diagnostic characterisation of appendicular bone tumours and tumour-like conditions. European Radiology, 17 (10): 2675-2686, 2007.

17- LEE Y.J., SADIGH S., MANKAD K., KAPSE N. and RAJESWARAN G.: The imaging of osteomyelitis. Quantitative imaging in medicine and surgery, 6 (2): 184, 2016.

18- BARNARDT P. and ROUX F.: The role of imaging in the evaluation of extraskeletal Ewing's sarcoma. SA Journal of Radiology, 17 (1), 2013.

19- KERALIYA A.R., KRAJEWSKI K.M., JAGANNATHAN J.P., SHINAGARE A.B., BRASCHI-AMIRFARZAN M., TIRUMANI S.H. and RAMAIYA N.H.: Multimodality imaging of osseous involvement In haematological malignancies. The British Journal of Radiology, 89 (1059): 20150980, 2016.

20- BIERRY G., KERR D.A., NIELSEN G.P., ROSENBERG A.E., HUANG A.J., TORRIANI M. and BREDELLA M.A.: Enchondromas in children: Imaging appearance with pathological correlation, 1223-1229, 2012.

21- MURPHEY M.D., JELINEK J.S., TEMPLE H.T., FLEMMING D.J. and GANNON F.H.: Imaging of Periosteal Osteosarcoma: Radiologic-Pathologic Comparison. Radiology, 233 (1): 129-138, 2004.

22- AKMAN B., ATA KORKMAZ H.A. and SAR1 A.: Efficacy of chemical shift MRI for differentiating diffuse red bone marrow reconversion and hematological malignancies. Turk. J. Med. Sci., 49 (2): 644-652. Published 2019 Apr 18. doi:10.3906/sag-1812-125, 2019.

23- AMIN, W.M., KOTB H.T., ABDEL-KERIM A.A., BARAKAT M.S., EL-MALKY A.A. and FADEL S.H.: Diffusion-weighted MRI and in-phase/opposed-phase sequences in the assessment of bone tumors. Journal of Magnetic Resonance Imaging, 44 (3): 565-572, 2016. 
24- OGURA A., HAYAKAWA K., MAEDA F., SAEKI F., SYUKUTANI A., SHIBUTANI S. and KURODA E. Differential diagnosis of vertebral compression fracture using in-phase/opposed-phase and short TI inversion recovery imaging. Acta Radiologica, 53 (4): 450-455, 2012.

25- WOOTTON-GORGES S.L.: MR imaging of primary bone tumors and tumor-like conditions in children. Magnetic Resonance Imaging Clinics of North America, 17 (3): 469-487, vi, 2009.

26- ROPPER A.E., CAHILL K.S., HANNA J.W., McCARTHY E.F., GOKASLAN Z.L. and CHI J.H.: Primary vertebral tumors: A review of epidemiologic, histological, and imaging findings, Part I: benign tumors. Neurosurgery, 69 (6): 1171-1180, 2011.

27- SHI Y.J., LI X.T., ZHANG X.Y., LIU Y.L., TANG L. and SUN Y.S.: Differential diagnosis of hemangiomas from spinal osteolytic metastases using 3.0 T MRI: Comparison of T1-weighted imaging, chemical-shift imaging, diffusion-weighted and contrast-enhanced imaging. Oncotarget, 8 (41): 71095, 2017

28- DOUIS H., DAVIES A.M., JEYS L. and SIAN P.: Chemical shift MRI can aid in the diagnosis of indeterminate skeletal lesions of the spine. European Radiology, 26 (4): 932-940, 2016.

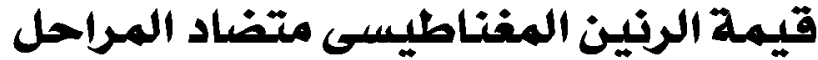 فى تقييم أورام العظام الخبيثينة}

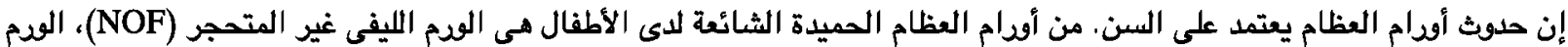

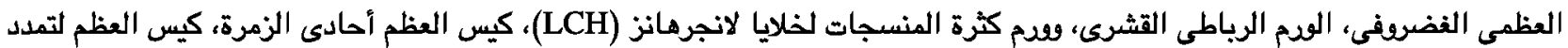

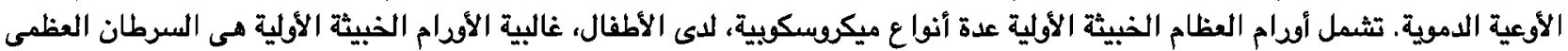

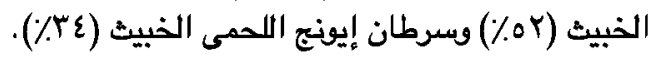

الأورام الخبية الثانوية فى العظام أكثر شيو عاً عند البالغين. غالباً ما تكنف الأورام الثانوية الذبيثة فى عظام الأطفال نتيجة الانتشار من سرطان الأرومة العصبية وسرطان الدم والأودرام اللمفاوية.

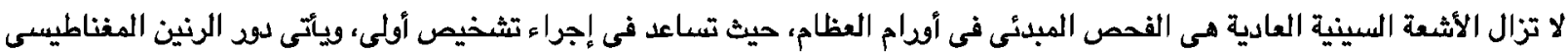

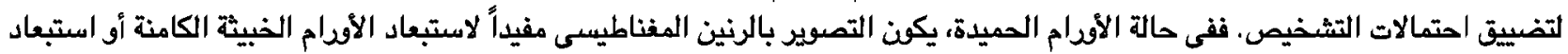

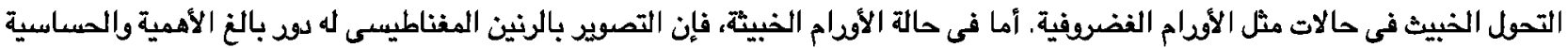

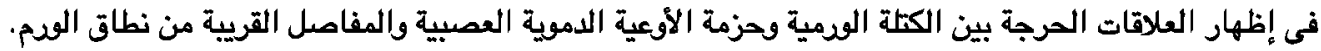

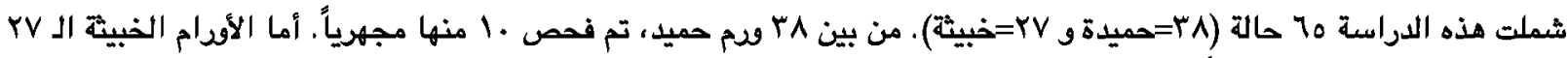
فقد تم التاكك من تشخيصها مجهرياً.

نحن نهدف إلى الكثف عن معايير التصوير بالرنين المغناطيسى بما فى ذلك التصوير بمتواليات الرنين المغناطيسى التقليدية والمحسنة

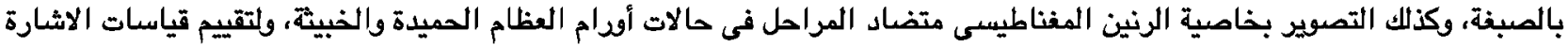
النسيية المختلفة للرنين المغناطيسى متضاد المراحل كاختبارات تشخيصية للتمييز بين الأورام الحميدة والخبيثة.

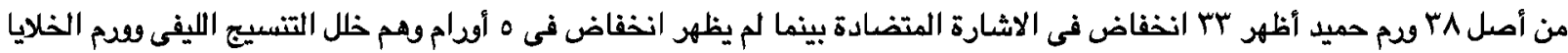

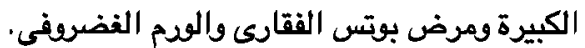

من ناحية أخرى، أظهر حج من الأورام الخييثة عدم انخفاض فى الاشارة المتضادة بينما أظهر ودم واحد انخفاضاً في الاشارة المتضادة

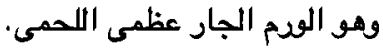

تم تصديد نقطة فاصلة إحصائية ما بين قيم الاشارة النسبية للرنين المغناطيسى متضاد المراحل للتفرقة ما بين الأودام الحميدة والخبيثة 